\title{
Función de los receptores de kainato en la regulación de la transmisión sináptica excitadora en el hipocampo
}

\author{
A. Rodríguez-Moreno
}

\author{
THE ROLE OF KAINATE RECEPTORS IN THE REGULATION OF \\ EXCITATORY SYNAPTIC TRANSMISSION IN THE HIPPOCAMPUS
}

\begin{abstract}
Summary. Aims. To describe the state of the art with regard to the physiology of kainate-like glutamate receptors as modulators in glutamatergic excitatory synaptic transmission in the hippocampus. Development. Kainate receptors modulate the release of glutamate in the hippocampus in the different synapses that have been studied to date. Their activation can produce a decrease or an increase in glutamate release according to the synapse under study and both types of modulation (increase or decrease) can take place even within the same synaptic connection, depending on the agonist concentration reached by the receptors. Thus, in the synapses that are established among the mossy fibres and the pyramidal neurones in region CA3, high concentrations (> $100 \mathrm{nM}$ ) of kainate trigger a drop in glutamate release, whereas low concentrations $(<50 \mathrm{nM})$ give rise to an increased release of the same neurotransmitter. These actions carried out by the kainate receptors are presynaptic and both ionotropic and metabotropic mechanisms have been proposed to explain them. Conclusions. Kainate receptors act in the hippocampus as modulators of glutamate release, by either increasing or decreasing it. They therefore help to keep the balance of neuronal excitability, also play a part in neuronal plasticity processes (LTP and LTD) and can trigger, under abnormal conditions, a notable imbalance of this excitability and give rise to epileptic-type firing patterns, among other disorders. [REV NEUROL 2006; 42: 282-7]
\end{abstract}

Key words. Glutamate. Hippocampus. Ionotropic. Kainate. Metabotropic. Receptors.

\section{INTRODUCCIÓN}

En la actualidad, está bien establecido que el glutamato es el agente neurotransmisor usado en la mayoría de las sinapsis excitadoras del sistema nervioso central (SNC) de los mamíferos. Además de la función del glutamato como mediador de la transmisión sináptica, este aminoácido participa durante la formación del sistema nervioso en procesos de crecimiento y maduración neuronal, en la formación y eliminación de sinapsis y, en determinadas áreas y de forma dependiente de actividad, en la formación de patrones precisos de conectividad sináptica. Igualmente desencadena cambios duraderos en la eficacia sináptica, fenómenos conocidos como potenciación de larga duración (LTP, del inglés long-term potentiation) y depresión de larga duración (LTD, del ingles long-term depression), que se consideran el correlato celular de los procesos de aprendizaje y formación de la memoria. Además, alteraciones de la neurotransmisión glutamatérgica están implicadas en el daño neuronal observado después de episodios de isquemia y de hipoglucemia, así como en la etiología de una serie de estados neurológicos patológicos que incluyen la epilepsia y las enfermedades de Alzheimer, de Parkinson, la corea de Huntington y la esclerosis lateral amiotrófica [1-9].

Los receptores que activa el glutamato se han dividido en dos familias: receptores metabotrópicos y receptores ionotrópi-

Aceptado tras revisión externa: 10.01 .06 .

División de Neurociencias. Centro Andaluz de Biología del Desarrollo. Universidad Pablo de Olavide. Sevilla, España.

Correspondencia: Dr. Antonio Rodríguez-Moreno. División de Neurociencias. Centro Andaluz de Biología del Desarrollo. Universidad Pablo de Olavide. Ctra. Utrera, km 1. E-41013 Sevilla. Fax: +34 954349 375. E-mail: arodmor@upo.es

Agradecimientos. Al Prof. Mauricio Valenzuela, por la lectura del manuscrito y su ayuda en la realización de alguna de las figuras.

(C) 2006, REVISTA DE NEUROLOGÍA cos. Los receptores metabotrópicos (mGluR) están acoplados a proteínas $\mathrm{G}$ (proteínas que unen GTP) y regulan la producción de mensajeros intracelulares [10]. Por el contrario, los receptores ionotrópicos de glutamato (iGluR) forman un canal catiónico con diferente selectividad iónica según el tipo de receptor, siendo permeables a sodio $\left(\mathrm{Na}^{+}\right)$, potasio $\left(\mathrm{K}^{+}\right) \mathrm{y}$, en ocasiones, calcio $\left(\mathrm{Ca}^{2+}\right)[11,12]$.

En función del agonista que produce la activación de éstos con mayor afinidad, los receptores ionotrópicos de glutamato se han clasificado en tres tipos: receptores de NMDA (ácido Nmetil-D-aspártico), receptores de AMPA (ácido $\alpha$-amino-3-hidroxi-5-metil-4-isoxazolepropiónico) y receptores de kainato.

\section{RECEPTORES DE KAINATO}

Como se describió en una revisión anterior [13], los receptores de kainato (KAR) constituyen el componente del sistema de señalización de glutamato que se ha mostrado más elusivo a los investigadores debido, sobre todo, a la falta de herramientas farmacológicas específicas que permitieran su detección en neuronas del SNC. Sólo recientemente se han definido los procesos en los cuales están involucrados estos receptores [14] gracias al desarrollo de las 2,3-benzodiacepinas como antagonistas de los receptores de AMPA [14]. La posterior demostración de que estos compuestos son selectivos para estos receptores $[15,16]$ ha sido crucial para el entendimiento de la función de los KAR.

\section{Familia de subunidades de receptores de kainato: GluR5-7, KA1 y KA2}

La familia de subunidades que puede contribuir a la formación de KAR nativos se puede dividir en dos subfamilias. Una primera incluye las subunidades GluR5, GluR6 y GluR7. Todas estas subunidades generan canales funcionales homoméricos. La otra subfamilia la constituyen las subunidades KA1 y KA2, las cuales no forman canales homoméricos. 


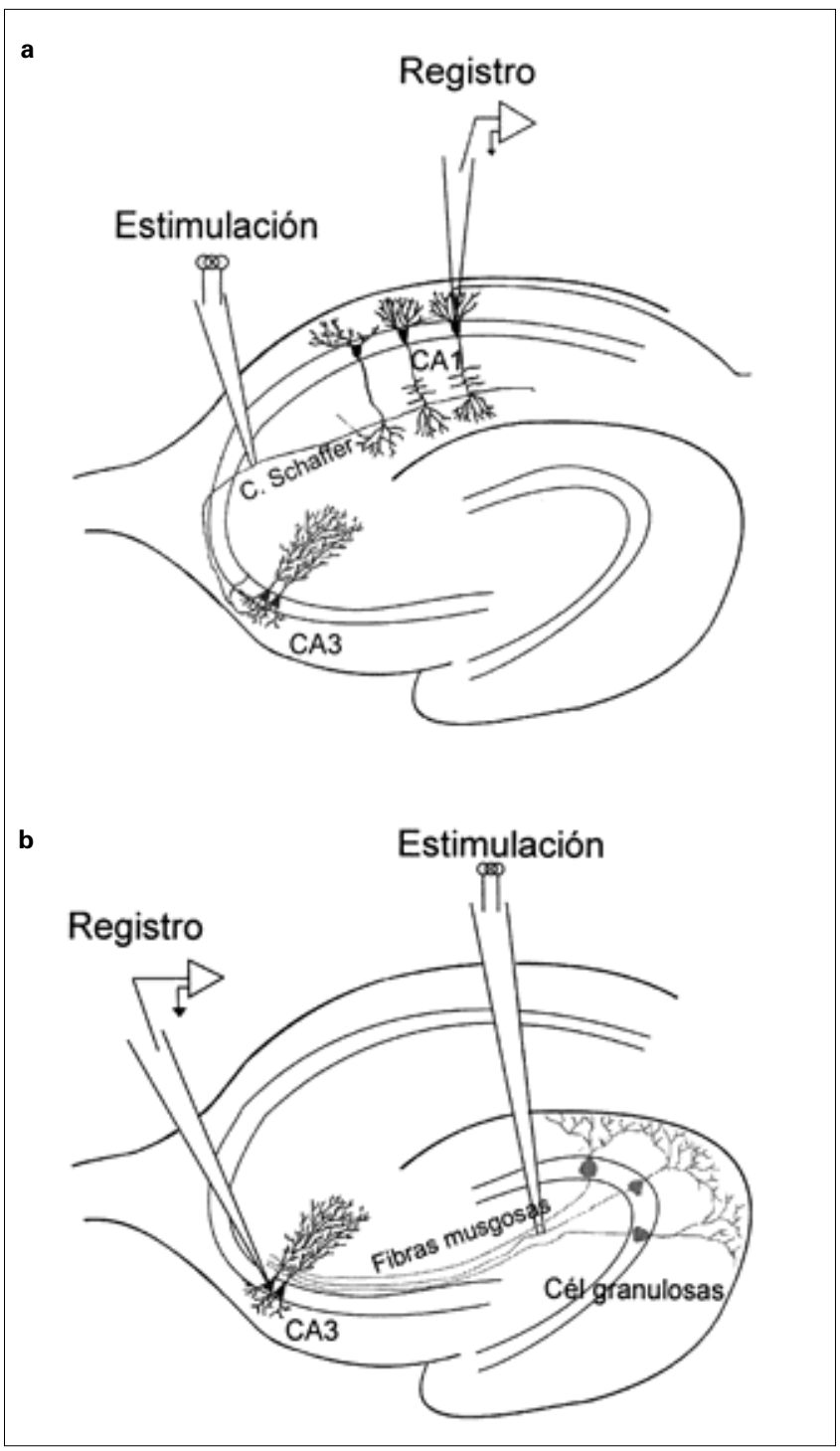

Figura 1. Diseño experimental utilizado para la obtención de registros en rodajas transversales de hipocampo: a) Producción de respuestas excitadoras provocadas en la región CA1 del hipocampo. Como se observa en la figura, el electrodo de estimulación se coloca sobre las colaterales de Schaffer y la pipeta de registro en las neuronas de CA1; b) Diseño para obtener las respuestas excitadoras en las células de CA3. El electrodo de estimulación se coloca sobre las fibras musgosas y los registros se obtienen de las células piramidales de CA3.

Desde el punto de vista molecular, los receptores ionotrópicos de glutamato son proteínas integrales de membrana formadas, probablemente, por cuatro subunidades que constituyen un tetrámero [17].

\section{Papeles fisiológicos de los receptores de kainato}

La disponibilidad del GYKI 53655 como antagonista selectivo de los receptores de AMPA ha hecho posible el estudio de la participación de los KAR como moduladores de la transmisión sináptica inhibidora [18], así como en la transmisión sináptica excitadora. Estudios en rodajas de hipocampo han permitido identificar una serie de sinapsis en las cuales los KAR parecen mediar una fracción pequeña de la corriente sináptica. En este sentido, se ha demostrado que pueden inducirse corrientes exci- tadoras postsinápticas (EPSC) con características farmacológicas propias de los KAR en las sinapsis formadas por las fibras musgosas y las neuronas piramidales de CA3 [19,20].

Además de en las neuronas principales de CA3, se ha identificado la presencia de receptores postsinápticos de kainato en neuronas de la amígdala lateral [21], en interneuronas del hipocampo [22,23], en neuronas del asta dorsal de la médula espinal [24], en algunas células bipolares de la retina [25], en el córtex cerebral [26] y en el cerebelo [27].

También se ha descrito que receptores de kainato situados en el terminal presináptico son capaces de modular la liberación de neurotransmisor. Así mismo se ha observado modulación -tanto aumento como disminución- de la liberación de GABA por la activación de este tipo de receptores [28-33].

Finalmente, se ha dedicado un gran esfuerzo en los últimos años a determinar qué papel desempeñan los KAR en la modulación de la transmisión excitadora glutamatérgica en el hipocampo. En esta revisión vamos a describir el efecto que tiene la activación de estos receptores sobre la transmisión excitadora, así como los mecanismos de acción involucrados.

\section{RECEPTORES DE KAINATO COMO MODULADORES DE LA TRANSMISIÓN SINÁPTICA GLUTAMATÉRGICA}

Actualmente, está bien establecido que la activación de KAR situados en la parte presináptica de los contactos excitadores puede producir una depresión de la liberación del neurotransmisor glutamato. En los últimos años se han aportado evidencias de que, además de este efecto, la activación de estos receptores puede producir un aumento de la liberación de glutamato cuando la concentración de agonista usada para la activación de los receptores es muy baja.

\section{Depresión de la transmisión sináptica glutamatérgica debida a la activación de receptores de kainato}

En 1996 se describió por primera vez que la activación de los receptores de glutamato de tipo kainato produce una depresión de la liberación de glutamato. La mayoría de los estudios del efecto del kainato sobre la transmisión glutamatérgica se han llevado a cabo en el hipocampo, siendo esta parte del cerebro donde mejor se conoce la función de estos receptores y en la que se centra esta revisión, concretamente en la sinapsis establecida entre las neuronas piramidales de CA 3 y CA1 por las colaterales de Schaffer (Fig. 1a) y la establecida entre los axones de las células granulosas del giro dentado (fibras musgosas) y las dendritas proximales de las neuronas piramidales de CA3 (Fig. 1b).

\section{Sinapsis colaterales de Schaffer-células piramidales de CAI}

En 1996, en experimentos llevados a cabo en sinaptosomas del hipocampo, Chittajallu et al [34] observaron que la aplicación de kainato -en condiciones de bloqueo del resto de receptores ionotrópicos de glutamato- produce, de forma dosisdependiente, una disminución de la liberación de glutamato. Estos autores, llevando a cabo además experimentos en rodajas transversales de hipocampo y monitorizando corrientes excitadoras postsinápticas provocadas (eEPSC) mediadas por receptores de tipo NMDA en presencia de GYKI 52466 -que bloquea los receptores de tipo AMPA, dejando inalterados los de kainato-, observaron que el kainato (1-30 $\mu \mathrm{M})$ producía una disminución de la amplitud media de las eEPSC, efecto que resultó reversible tras el lavado de kainato. 
Este efecto del kainato fue antagonizado por CNQX -antagonista competitivo de los receptores de AMPA y de kainato- en condiciones en las que la activación de los receptores de AMPA se había evitado previamente por la acción de GYKI 52655, indicando por tanto que esta acción es efectivamente mediada por la activación de receptores de glutamato de tipo kainato.

Resultados similares fueron obtenidos por Kamiya et al [35], quienes también estudiaron la sinapsis formada por las colaterales de Schaffer sobre las neuronas principales de CA1 en ratas de 14-21 días. Estos autores encontraron que $1 \mu \mathrm{M}$ de kainato produce una disminución de la amplitud media de los potenciales postsinápticos excitadores provocados (fEPSP). También observaron que la facilitación por pares de pulsos aumenta en presencia de kainato. Estos cambios en la facilitación por pares de pulsos indican que el efecto del kainato podría ser presináptico. Vignes et al [36] sugieren que este efecto de deprimir la amplitud media de los fEPSP está mediado por la activación de KAR formados por la subunidad GluR5, al encontrar que ATPA, sustancia propuesta por estos autores como antagonista selectivo para GluR5, produce el mismo efecto que la aplicación de kainato.

Frerking et al [37] confirmaron y extendieron las evidencias de una modulación presináptica de la liberación de glutamato en la sinapsis colaterales de Schaffer-CA1 al encontrar que el domoato -un agonista específico de los receptores de kainato en dosis bajas, del orden de nanomoles- produce una reducción de la amplitud de las eEPSC mediada por la activación de receptores de NMDA en condiciones de bloqueo de los receptores de AMPA. Al mismo tiempo, hallaron que el domoato producía un aumento de la facilitación por pares de pulsos, un cambio en el estadístico $1 / \mathrm{CV}^{2}$ (una estimación de la varianza de las respuestas provocadas) que correlacionaba con la disminución de la amplitud de los fEPSP (según el modelo cuántico de liberación de neurotransmisor, si ambas variables cambian de forma directamente proporcional, la explicación más probable para los cambios observados es una variación en parámetros presinápticos, ya sean probabilidad de liberación y/o cambio en el número de sitios de liberación), y no hallaron cambio alguno en la amplitud de las corrientes miniatura (mEPSC) tras la aplicación de domoato. Todos estos resultados sugieren un mecanismo de acción presináptico para esta depresión de la amplitud media de las eEPSC o fEPSP e indican que el kainato produce una disminución de la liberación de glutamato en los terminales presinápticos.
Mecanismo de acción de los KAR para producir una depresión de la liberación de glutamato en la sinapsis colaterales de Schaffer-CA1. Kamiya et al [35], realizando estudios simultáneos de los cambios de la amplitud de los fEPSP y de entrada de calcio en los terminales sinápticos, llegaron a la conclusión de que los KAR producen una depresión de la liberación de glutamato debido a que originan una disminución de la entrada de calcio en los terminales presinápticos.

Frerking et al [37] propusieron que la depresión de la liberación de glutamato observada no se debe a una acción ionotrópica de los KAR, sino que (al igual que se propuso unos años antes para la liberación de GABA) involucra una acción metabotrópica de estos receptores. Así, encuentran que la acción depresora no está presente en rodajas tratadas con toxina pertúsica, lo que indica que una proteína $\mathrm{G}_{\mathrm{i}} / \mathrm{G}_{\mathrm{o}}$ está involucrada en dicha acción. A diferencia del mecanismo descrito por RodríguezMoreno et al [29] para la liberación de GABA, la depresión de la liberación de glutamato no involucra la activación de la proteincinasa C (PKC) ni de la proteincinasa A (PKA), ya que la depresión de la liberación de glutamato mediada por los KAR persiste cuando las rodajas se trataron con $\mathrm{H}-7$, un inhibidor de amplio espectro de proteincinasas. 


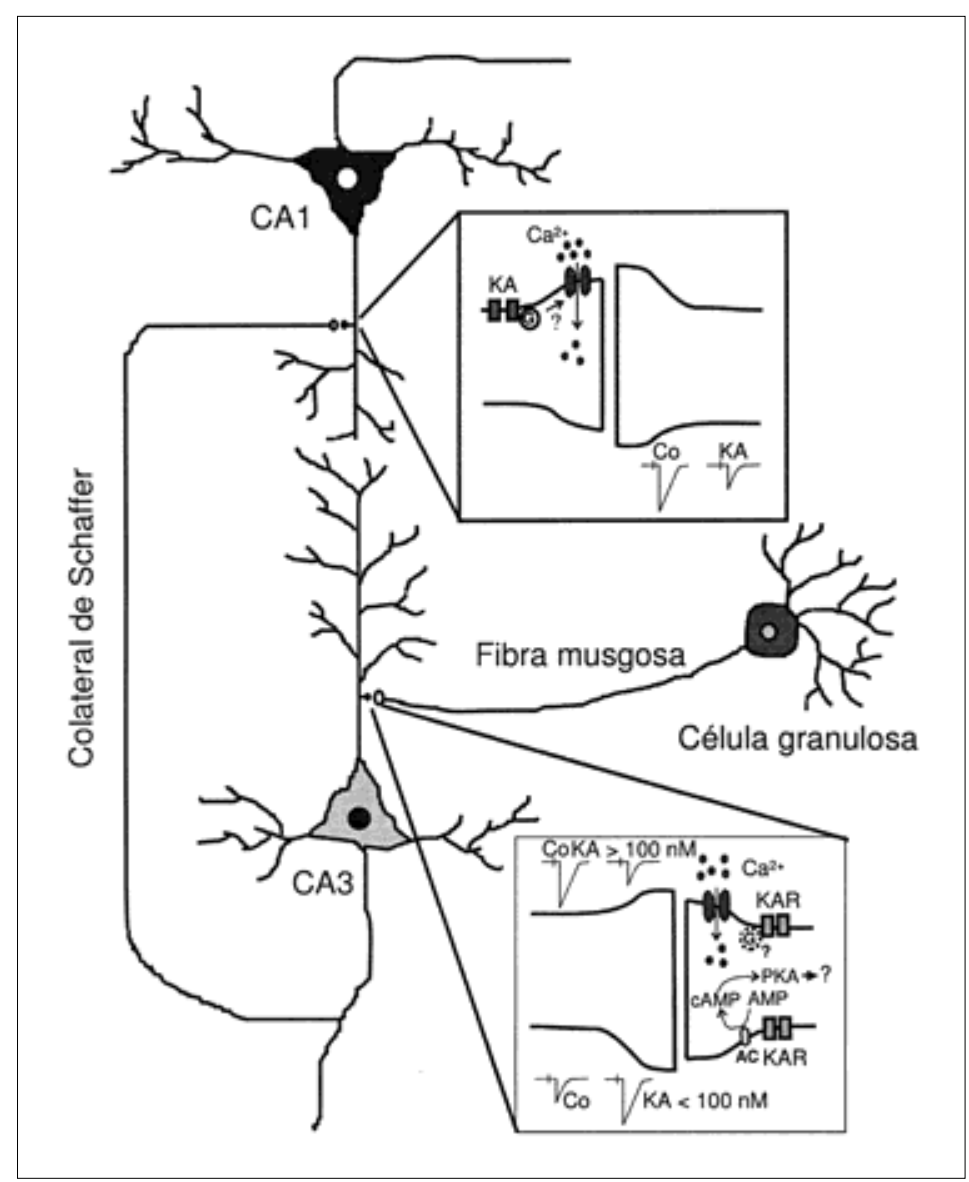

Figura 3. Esquema ilustrativo de los mecanismos de acción descritos para las acciones del kainato sobre sus receptores presinápticos en el hipocampo.

\section{Sinapsis fibras musgosas-células piramidales de CA3}

En la sinapsis fibra musgosa-CA3 (MF-CA3), al igual que en la descrita anteriormente (colaterales de Schaffer-CA1), se ha observado que concentraciones micromolares de kainato producen una disminución en la amplitud media de las eEPSC [38-40].

Kamiya et al [38] fueron los primeros en describir que la activación de los KAR produce una disminución media de las eEPSC o fEPSP en esta sinapsis. Estos autores encontraron que la aplicación de kainato produce de forma reversible una disminución de la amplitud media de las eEPSC en condiciones de bloqueo del resto de los receptores de glutamato. Además, hallaron cambios en el componente de descarga de las fibras (fiber volley), lo que sugería que la acción de estos receptores podría ser presináptica. Contractor et al [40] encontraron similares resultados y además realizaron estudios sobre el número de fallos (el kainato produce una disminución en el porcentaje de éstos) y la facilitación por pares de pulsos (que aumenta, lo cual sugiere una disminución de la probabilidad de liberación), ambos indicativos de un mecanismo de acción presináptico. Schmitz et al [39] demostraron que el agonista endógeno de estos receptores, el glutamato, tiene acceso a los KAR presinápticos de las fibras musgosas, produciendo el mismo efecto que el kainato.

Mecanismo de acción de los KAR involucrados en la disminución de la liberación de glutamato en la sinapsis MF-CA3. Kamiya et al [38], realizando estudios de fluorescencia y electrofisiológicos, propusieron una disminución en la entrada de calcio como causa de esta depresión de la transmisión presináptica al observar que el kainato produce una marcada disminución de la entrada de calcio en el terminal presináptico $\mathrm{y}$, al mismo tiempo, disminuye la amplitud media de los fEPSP. Schmitz et al [39] observaron que la aplicación de altas concentraciones de potasio extracelular depolariza los terminales y produce una disminución de la amplitud media de las respuestas postsinápticas similar a la producida por el kainato; concluyen que el efecto del kainato se debe a una depolarización de los terminales y sugieren que una posterior inactivación de los canales de $\mathrm{Ca}^{2+}$ mediada por un mecanismo ionotrópico o metabotrópico podría ser la responsable de este efecto. En la actualidad, no se dispone de datos que demuestren si el mecanismo de acción para producir este efecto se debe a una acción ionotrópica o metabotrópica de los KAR.

\section{Aumento de la transmisión sináptica glutamatérgica debida a la activación de receptores de kainato}

Existen evidencias de un aumento de la transmisión sináptica glutamatérgica por activación de KAR presinápticos en el hipocampo en la sinapsis MF-CA3. En algunos casos se propone un efecto bifásico del kainato, de forma que en bajas concentraciones (submicromolares), el kainato produce una facilitación de la liberación de glutamato y, en concentraciones más elevadas, origina una depresión de ésta.

Contractor et al [41], Schmitz et al [42] y Lauri et al [43] fueron los primeros en mostrar que concentraciones de 20-50 nM de kainato producen de forma reversible un aumento de la liberación de glutamato en la sinapsis MF-CA3, y que este aumento es responsable de la marcada facilitación por pares de pulsos que muestran estas sinapsis. Para zanjar la polémica referente a la localización pre o postsináptica de los receptores responsables de esta acción del kainato, Rodríguez-Moreno et al [44] realizaron experimentos en sinaptosomas (preparaciones en las cuales la presencia de membranas postsinápticas es mínima o inexistente) del hipocampo y observaron que, en condiciones de bloqueo de los receptores de AMPA, el kainato produce un aumento de la liberación de glutamato. Igualmente realizaron el estudio en rodajas de hipocampo y observaron -además del aumento de la amplitud de las eEPSC mediado por la activación de KAR (Figs. 2a y 2b)que el análisis del cambio del coeficiente de variación (una medida de la varianza de las respuestas provocadas) con respecto al cambio de la media de las mismas respuestas tras la adición de kainato es congruente con un mecanismo de acción presináptico (Fig. 2c).

Mecanismo de acción de los KAR involucrados en la facilitación de la liberación de glutamato en la sinapsis $M F-C A 3$

Lauri et al [45] descartaron que esta facilitación estuviera mediada por la activación de la PKC, ya que persiste en rodajas tratadas con calfostina C, un inhibidor selectivo de la PKC.

En 2004, Rodríguez-Moreno et al [44] realizaron un estudio detallado del aumento de la amplitud media de las eEPSC producida por la activación de receptores de kainato y determinaron que el efecto de facilitar la liberación de glutamato mediado por la activación de KAR involucra la activación de la PKA, ya que el efecto del kainato disminuye de forma conside- 
rable o desaparece completamente cuando las rodajas se tratan con H-89 o Rp-Br-cAMP, inhibidores específicos de la PKA (Fig. 2d). También sugirieron la participación en esta acción de la adenilato ciclasa, ya que el terpeno forscolina (potente activador de la adenilato ciclasa) produce un aumento de la liberación de glutamato, y el kainato, en presencia de esta sustancia, no origina un incremento adicional de la liberación de glutamato, lo que muestra una oclusión completa del efecto del kainato por la forscolina e indica que ambas sustancias ejercen su acción compartiendo la misma ruta intracelular (Fig. 2e). Estos resultados se obtuvieron tanto en sinaptosomas como en rodajas, indicando por tanto que no constituyen un mecanismo inherente a la preparación usada, sino que obedecen a un mecanismo general. Rodríguez-Moreno et al [44] también demostraron que la activación de la adenilato ciclasa no se produce por la activación por parte de los KAR de una proteína G, puesto que en rodajas tratadas con las toxinas pertúsica y colérica persisten los efectos facilitadores de la liberación de glutamato mediada por kainato.

\section{CONCLUSIONES}

Los KAR participan de forma clara en la modulación de la liberación de glutamato en diferentes regiones del hipocampo. La mayoría de las evidencias disponibles indican un modo presináptico de acción para esta modulación. La activación de los citados receptores puede producir tanto un aumento como una disminución de la liberación de glutamato, en función del tipo de sinapsis e incluso dentro de la misma conexión sináptica, dependiendo de la concentración de agonista que alcanza al receptor. Así, en la sinapsis MF-CA3, dependiendo de la concentración de kainato, se produce un aumento (en dosis $<100 \mathrm{nM}$ de kainato) o una disminución (en dosis > $100 \mathrm{nM}$ ) de la liberación de glutamato; queda por determinar si es el mismo complejo receptor quien lleva a cabo ambas funciones o son KAR diferentes. Se han propuesto diferentes mecanismos para esta acción presináptica de los KAR, tanto ionotrópicos como metabotrópicos. Así, para la disminución de la liberación de glutamato en la sinapsis entre los axones de las piramidales de CA3 (colaterales de Schaffer) y las células principales de CA1, se ha propuesto un mecanismo de acción metabotrópico (en esta sinapsis no se ha descrito hasta el momento un aumento de la liberación mediada por KAR) y una acción mediada por la PKA para el aumento de liberación en la sinapsis MF-CA3 (que hasta ahora no se ha descrito sensible a proteínas G), y se ha sugerido un mecanismo -metabotrópico o no- que involucra la inactivación de canales de calcio como responsable de la disminución de la liberación de glutamato también observada en esta última sinapsis (Fig. 3).

Los resultados descritos dan una idea de la participación de los KAR en la regulación de la excitabilidad de las neuronas principales del hipocampo, contribuyendo en condiciones normales a la adecuada regulación de esa excitabilidad. Experimentos futuros contribuirán a determinar, de forma fehaciente y completa, los mecanismos de acción de estos receptores, incluyendo las cascadas de reacciones intracelulares en que participan, así como las consecuencias fisiológicas de esta modulación en la liberación del neurotransmisor glutamato.

\section{BIBLIOGRAFÍA}

1. Eubanks JH, Puranam RS, Kleckner NW, Bettler B, Heinemann SF, McNamara JO. The gene encoding the glutamate receptor subunit GluR5 is located on human chromosome 21q21.1-22.1 in the vicinity of the gene for familial amyotrophic lateral sclerosis. Proc Natl Acad Sci U S A 1993; 90: 178-82.

2. Jonas P, Monyer H. Ionotropic glutamate receptors in the CNS. Berlin: Springer; 1999.

3. MacDonald ME, Vonsattel JP, Shrinidhi J, Couropmitree NN, Cupples LA, Bird ED, et al. Evidence for the GluR6 gene associated with younger onset age of Huntington's disease. Neurology 1999; 53: 1330-2.

4. Mulle C, Sailer A, Pérez-Otaño I, Dickinson-Anson H, Castillo PE, Bureau I, et al. Altered synaptic physiology and reduced susceptibility to kainate-induced seizures in GluR6-deficient mice. Nature 1998; 392: 601-5.

5. Rubinsztein DC, Leggo J, Chiano M, Dodge A, Norbury G, Rosser E, et al. Genotypes at the GluR6 kainate receptor locus are associated with variation in the age of onset of Huntington disease. Proc Natl Acad Sci U S A 1997; 94: 3872-6.

6. Sander T, Hildmann R, Kretz R Fürst U, Sailer G, Bauer B, et al. Allelic association of juvenile absence epilepsy with a GluR5 kainate receptor gene (GRIK1) polymorphism. Am J Med Genet 1997; 74: 416-21.

7. Sander T, Janz D, Ramel C, Ross CA, Paschen W, Hildmann T, et al. Refinement of map position of the human GluR6 kainate receptor gene (GRIK2) and lack of association and linkage with idiopathic generalized epilepsies. Neurology 1995; 45: 1713-20.

8. Teitelbaum JS, Zatorre RJ, Carpenter S, Gendron SD, Evans A, Gjedde A, et al. Neurologic sequelae of domoic acid intoxication due to the ingestion of contaminated mussels. N Engl J Med 1990; 322: 1781-7.

9. Armijo JA, De las Cuevas I, Adín J. Canales iónicos y epilepsia. Rev Neurol 2000; 30 (Supl): S25-41.

10. Pin JP, Duvoisin R. The metabotropic glutamate receptors: structure and function. Neuropharmacology 1995; 34: 1-26.

11. Nakanishi S. Molecular diversity of glutamate receptors and implications for brain function. Science 1992; 258: 597-603.

12. Hollmann M, Heinemann S. Cloned glutamate receptors. Annu Rev Neurosci 1994; 17: 31-108.

13. Rodríguez-Moreno A. Receptores de kainato. Función en la regulación de la transmisión sináptica gabérgica en el hipocampo. Rev Neurol 2003; 36: $852-9$.
14. Lerma J, Paternain AV, Rodríguez-Moreno A, López-García JC. Molecular physiology of kainate receptors. Physiol Rev 2001; 81: 971-98.

15. Vizi E, Mike SA, Tarnawa I. 2,3-Benzodiazepines (GYKI 52466 and analogs): negative allosteric modulators of AMPA receptors. CNS Drug Rev 1996; 2: 91-126.

16. Paternain AV, Morales M, Lerma J. Selective antagonism of AMPA receptors unmasks kainate receptor-mediated responses in hippocampal neurons. Neuron 1995; 14: 185-9.

17. Wilding TJ, Huettner JE. Differential antagonism of $\alpha$-amino-3-hydroxy5-methyl-4-isoxazolepropionic acid-preferring and kainate-preferring receptors by 2,3-benzodiazepines. Mol Pharmacol 1995; 47: 582-7.

18. Rosenmund C, Stern-Bach Y, Stevens CF. The tetrameric structure of a glutamate receptor channel. Science 1998; 280: 1596-9.

19. Castillo PE, Malenka RC, Nicoll RA. Kainate receptors mediate a slow postsynaptic current in hippocampal CA3 neurons. Nature 1997; 388: $182-6$.

20. Vignes M, Collingridge GL. The synaptic activation of kainate receptors. Nature 1997; 388: 179-82.

21. Li H, Rogawski MA. GluR5 kainate receptor mediated synaptic transmission in rat basolateral amygdala in vitro. Neuropharmacology 1998; 37: 1279-86.

22. Cossart RM, Esclapez M, Hirsch JC, Bernard C, Ben-Ari Y. GluR5 kainate receptor activation in interneurons increases tonic inhibition of pyramidal cells. Nat Neurosci 1998; $1:$ 470-8.

23. Frerking MR, C. Malenka C, Nicoll RA. Synaptic activation of kainate receptors on hippocampal interneurons. Nat Neurosci 1998; 1: 479-86.

24. Li P, Wilding TJ, Kim SJ, Calejesan AA, Huettner JE, Zhuo M. Kainate-receptor-mediated sensory synaptic transmission in mammalian spinal cord. Nature 1999; 397: 161-4.

25. DeVries SH, Schwartz EA. Kainate receptors mediate synaptic transmission between cones and 'off' bipolar cells in a mammalian retina. Nature 1999; 397: 157-60.

26. Kidd FL, Isaac JTR. Developmental and activity-dependent regulation of kainate receptors at thalamocortical synapses. Nature 1999; 400: 569-73.

27. Bureau I, Bischoff S, Heinemann SF, Mulle C. Kainate receptor-mediated responses in the CA1 field of wild-type and GluR6-deficient mice. J Neurosci 1999; 19: 653-63. 
28. Rodríguez-Moreno A, Herreras O, Lerma J. Kainate receptors presynaptically downregulate GABAergic inhibition in the rat hippocampus. Neuron 1997; 19: 893-901.

29. Rodríguez-Moreno A, Lerma J. Kainate receptor modulation of GABA release involves a metabotropic function. Neuron 1998; 20: 1211-8.

30. Rodríguez-Moreno A, López-García JC, Lerma J. Two populations of kainate receptors with separate signaling mechanisms in hippocampal interneurons. Proc Natl Acad Sci U S A 2000; 97: 1293-8.

31. Cossart R, Tyzio R, Dinocourt C, Esclapez M, Hirsch JC, Ben-Ari Y, et al. Presynaptic kainate receptors that enhance the release of GABA on CA1 hippocampal interneurons. Neuron 2001; 29: 497-508.

32. Jiang L, Xu J, Nedergaard M, Kang J. A kainate receptor increases the efficacy of GABAergic synapses. Neuron 2001; 30; 503-13.

33. Rodríguez-Moreno A. Papel de los receptores de kainato en la regulación de la transmisión sináptica gabérgica [tesis doctoral]. Madrid: Universidad Autónoma de Madrid; 2000.

34. Chittajallu R, Vignes M, Dev KK, Barnes JM, Collingridge GL, Henley JM. Regulation of glutamate release by presynaptic kainate receptors in the hippocampus. Nature 1996; 379: 78-81.

35. Kamiya H, Ozawa S. Kainate receptor-mediated inhibition of presynaptic $\mathrm{Ca}^{2+}$ influx and EPSP in area CA1 of the rat hippocampus. J Physiol 1998; 509: 833-45.

36. Vignes M, Clarke VRJ, Parry MJ, Bleakman D, Lodge D, Ornstein, PL, et al. The GluR5 subtype of kainate receptor regulates excitatory synaptic transmission in areas CA1 and CA3 of the rat hippocampus. Neuropharmacology 1998; 37: 1269-77.

37. Frerking M, Schmitz D, Zhou Q, Johansen, Nicoll RA. Kainate receptors depress excitatory synaptic transmission at $\mathrm{CA} 3 \rightarrow \mathrm{Ca} 1$ synapses in

\section{FUNCIÓN DE LOS RECEPTORES DE KAINATO \\ EN LA REGULACIÓN DE LA TRANSMISIÓN \\ SINÁPTICA EXCITADORA EN EL HIPOCAMPO}

Resumen. Objetivo. Describir el estado actual de conocimientos sobre la fisiología de los receptores de glutamato de tipo kainato como moduladores de la transmisión sináptica excitadora glutamatérgica en el hipocampo. Desarrollo. Los receptores de kainato modulan la liberación de glutamato en el hipocampo en las distintas sinapsis estudiadas hasta el momento. Su activación puede producir una disminución o un aumento de la liberación de glutamato en función de la sinapsis estudiada e incluso dentro de la misma conexión sináptica pueden dar lugar a ambos tipos de modulación (aumento o disminución), dependiendo de la concentración de agonista que alcanza a los receptores. Así, en la sinapsis establecida entre las fibras musgosas y las neuronas piramidales de la región CA3, concentraciones elevadas (> $100 \mathrm{nM}$ ) de kainato producen una disminución de la liberación de glutamato, mientras que concentraciones pequenas ( $<50 \mathrm{nM})$ producen un incremento de la liberación del mismo neurotransmisor. Estas acciones de los receptores de kainato son presinápticas y para ellas se han propuesto mecanismos tanto ionotrópicos como metabotrópicos. Conclusiones. Los receptores de kainato actúan en el hipocampo como moduladores de la liberación de glutamato, aumentándola o disminuyéndola; contribuyen así al mantenimiento del equilibrio de la excitabilidad neuronal, participan además en procesos de plasticidad neuronal (LTP y LTD) y pueden producir, en condiciones anormales, un marcado desequilibrio de esta excitabilidad y dar lugar, entre otras alteraciones, a patrones de disparo de tipo epiléptico. [REV NEUROL 2006; 42: 282-7] Palabras clave. Glutamato. Hipocampo. Ionotrópico. Kainato. Metabotrópico. Receptores. the hippocampus via a direct presynaptic action. J Neurosci 2001; 21: 2958-66.

38. Kamiya H, Ozawa S. Kainate receptor-mediated presynaptic inhibition at the mouse hippocampal mossy fibre synapse. J Physiol 2000; 523 (Pt 3): 653-5.

39. Schmitz J, Frerking M, Nicoll RA. Synaptic activation of presynaptic kainate receptors on hippocampal mossy fiber synapses. Neuron 2000; 27: 327-38.

40. Contractor A, Swanson GT, Sailer A, O’Gorman S, Heinemann SF. Identification of the kainate receptors subunit underlying modulation of excitatory synaptic transmission in the CA3 region of the hippocampus. J Neurosci 2000; 20: 8269-78.

41. Contractor A, Swanson GT, Heinemann SF. Kainate receptors are involved in short- and long-term plasticity at mossy fiber synapses in the hippocampus. Neuron 2001; 29: 209-16.

42. Schmitz D, Mellor J, Nicoll RA. Presynaptic kainate receptor mediation of frequency facilitation at hippocampal mossy fiber synapses. Science 2001; 291: 1972-6.

43. Lauri SE, Delany C, Clarke VEJ, Bortolotto ZA, Ornstein PL, Isaac JT, et al. Synaptic activation of a presynaptic kainate receptor facilitates AMPA receptor-mediated synaptic transmission at hippocampal mossy fibre synapses. Neuropharmacology 2001; 41: 907-15.

44. Rodríguez-Moreno A, Sihra TS. Presynaptic kainate receptor facilitation of glutamate release involves protein kinase $\mathrm{A}$ in the rat hippocampus. J Physiol 2004; 557: 733-45.

45. Lauri SE, Bortolotto ZA, Bleakman D, Ornstein PL, Lodge D, Isaac JT, et al. A critical role of a facilitatory presynaptic kainate receptors in mossy-fiber LTP. Neuron 2001; 32: 697-709.

\section{FUNÇÃO DOS RECEPTORES DE KAINATO NA REGULAÇÃO DA TRANSMISSÃO SINÁPTICA EXCITADORA NO HIPOCAMPO}

Resumo. Objectivo. Descrever o estado actual de conhecimento sobre a fisiologia dos receptores de glutamato de tipo kainato como moduladores da transmissão sináptica excitadora glutamatérgica no hipocampo. Desenvolvimento. Os receptores de kainato modulam a libertação de glutamato no hipocampo nas diferentes sinapses estudadas até ao momento. A sua activação pode levar a uma diminuição ou a um aumento da libertação de glutamato em função da sinapse estudada e inclusivamente, dar lugar a ambos os tipos de modulação dentro da mesma conexão sináptica (aumento ou diminuição), dependendo da concentração de agonista que chega aos receptores. Assim, na sinapse estabelecida entre as fibras musgosas e os neurónios piramidais da região CA3, concentrações elevadas (> $100 \mathrm{nM}$ ) de kainato produzem uma diminuição da libertação de glutamato, enquanto que as concentrações baixas ( $<50 \mathrm{nM})$ produzem um aumento da libertação do mesmo neurotransmissor. Estas acções dos receptores de kainato são pré-sinápticas e para elas propuseram-se mecanismos, tanto ionotrópicos como metabotrópicos. Conclusões. Os receptores de kainato actuam no hipocampo como moduladores da libertação de glutamato, aumentando-a ou diminuindo-a; contribuem assim para a manutenção do equilíbrio da excitabilidade neuronal, participando para além disso em processos de plasticidade neuronal (LTP e LTD) podendo produzir, em condições anormais, um desequilíbrio marcado desta excitabilidade, dando lugar, entre outras alterações, a padrões de descarga de tipo epiléptico. [REV NEUROL 2006; 42: 282-7]

Palavras chave. Glutamato. Hipocampo. Ionotrópico. Kainato. Metabotrópico. Receptores. 